\title{
Inhibitory Effects of Pretreatment with Radon on Acute Alcohol-Induced Hepatopathy in Mice
}

\author{
Teruaki Toyota, ${ }^{1,2}$ Takahiro Kataoka, ${ }^{1}$ Yuichi Nishiyama, ${ }^{1}$ \\ Takehito Taguchi, ${ }^{1}$ and Kiyonori Yamaoka ${ }^{1}$ \\ ${ }^{1}$ Graduate School of Health Sciences, Okayama University, 5-1 Shikata-cho, 2-chome, Okayama 700-8558, Japan \\ ${ }^{2}$ Department of Radiation Research Shikata Laboratory, Advanced Science Research Center, Okayama University, \\ 5-1 Shikata-cho, 2-chome, Okayama 700-8558, Japan
}

Correspondence should be addressed to Kiyonori Yamaoka, yamaoka@md.okayama-u.ac.jp

Received 3 July 2012; Accepted 13 October 2012

Academic Editor: Antonio Macciò

Copyright (C) 2012 Teruaki Toyota et al. This is an open access article distributed under the Creative Commons Attribution License, which permits unrestricted use, distribution, and reproduction in any medium, provided the original work is properly cited.

\begin{abstract}
We previously reported that radon inhalation activates antioxidative functions in the liver and inhibits carbon tetrachlorideinduced hepatopathy in mice. In addition, it has been reported that reactive oxygen species contribute to alcohol-induced hepatopathy. In this study, we examined the inhibitory effects of radon inhalation on acute alcohol-induced hepatopathy in mice. C57BL/6J mice were subjected to intraperitoneal injection of $50 \%$ alcohol ( $5 \mathrm{~g} / \mathrm{kg}$ bodyweight) after inhaling approximately $4000 \mathrm{~Bq} / \mathrm{m}^{3}$ radon for $24 \mathrm{~h}$. Alcohol administration significantly increased the activities of glutamic oxaloacetic transaminase (GOT), glutamic pyruvic transaminase (GPT) in serum, and the levels of triglyceride and lipid peroxide in the liver, suggesting acute alcohol-induced hepatopathy. Radon inhalation activated antioxidative functions in the liver. Furthermore, pretreatment with radon inhibited the depression of hepatic functions and antioxidative functions. These findings suggested that radon inhalation activated antioxidative functions in the liver and inhibited acute alcohol-induced hepatopathy in mice.
\end{abstract}

\section{Introduction}

Radon is a radioactive gaseous element that mainly emits $\alpha$ rays. On entry through the lungs or skin, it reaches the blood stream and is then distributed throughout the body. If radon is inhaled, the lungs will be subjected to the actions of free radicals created by radiation and may suffer inflammation. Although radon inhalation has been thought to be hazardous in general, a large number of patients are treated in various countries with traditional radon spa therapy (Japan [1-4], central Europe [5]). In particular, therapy involving radon gas volatilized from radon-enriched water is performed for various diseases at Misasa Medical Center, Okayama University Hospital $[1,6]$. The most common diseases treated with radon therapy are arteriosclerosis, osteoarthritis [1], and bronchial asthma [6], which are related to reactive oxygen species (ROS). To assess the effects of radon, we developed a radon-exposure system and conducted several studies. For example, in the search for new indications for radon therapy, we reported the responsiveness to radon of an antioxidant enzyme (a radical scavenger), superoxide dismutase (SOD), in mouse organs [7], and suggested that radon inhalation activated antioxidative functions in many organs of mice. In addition, it was demonstrated that radon inhalation has anti-inflammatory effects and inhibits carrageenan-induced inflammatory paw edema [8]. Furthermore, a clinical study was conducted using thoron, which is an isotope of radon. The results suggested that thoron and thermal treatment activate antioxidative functions, and that thoron and thermal treatment prevent diabetic ketoacidosis [3]. Thus, it is likely that radon therapy would be useful for several diseases. In particular, radon therapy is less stressful than other therapies because it is a colorless, tasteless, and odorless gas. On the other hand, several reports have indicated the health risks of high-level radon, especially for the lungs and skin [9-11]; however, in radon therapy at Misasa, therapeutic exposure doses within the range of $50-67 \mu \mathrm{Sv}$ are lower than the average annual amount of natural radiation $(2.4 \mathrm{mSv})$ [12]. Additionally, according to Sakoda's report [13], the dose 
absorbed by the lungs was $300 \mathrm{nGy}$ and by the skin was $152 \mathrm{nGy}$ under the conditions of this study.

ROS, such as hydrogen peroxide $\left(\mathrm{H}_{2} \mathrm{O}_{2}\right)$, hydroxyl radical $\left({ }^{-} \mathrm{OH}\right)$, and superoxide anion radicals $\left(\mathrm{O}_{2}{ }^{-}\right)$, damage DNA, lipids, and enzymes and are highly toxic. Cells can be injured or killed when the ROS level exceeds the cellular antioxidant capacity. For example, there is evidence that oxidative stress plays an important role in the development of alcoholic liver disease [14-17]. Alcohol administration has been found to cause the accumulation of ROS, including $\mathrm{O}_{2}{ }^{-},{ }^{-} \mathrm{OH}$, and $\mathrm{H}_{2} \mathrm{O}_{2}$, and to increase lipid peroxide levels in the liver.

Although hepatic damage is not the main indication for radon therapy, our previous study demonstrated that radon inhalation clearly inhibited carbon tetrachloride $\left(\mathrm{CCl}_{4}\right)$-induced hepatopathy [18]; however, it is unlikely that humans will suffer from $\mathrm{CCl}_{4}$-induced hepatopathy. In contrast, alcohol-induced hepatopathy is a common contemporary disease. In our previous study, mice inhaled radon immediately after alcohol intake to demonstrate the relation between alcohol metabolism and the activation of antioxidative functions in the liver and brain by radon inhalation [19]. These findings suggest that radon inhalation activated antioxidative functions in the liver and brain of mice, but the brain was more susceptible to oxidation by radon than the liver.

The purpose of this study was to assess whether pretreatment with radon inhibits acute alcohol-induced hepatopathy in mice. The following biochemical and histological parameters were examined to assess the effects of radon treatment on antioxidative functions: SOD, catalase, total glutathione content (t-GSH), glutathione peroxidase (GPx) and glutathione reductase (GR) activities, lipid peroxide levels in the liver, glutamic oxaloacetic transaminase (GOT), glutamic pyruvic transaminase (GPT), triglyceride level (TG) total cholesterol (T-CHO) in serum, TG in the liver, and histological examination of liver tissue.

\section{Materials and Methods}

2.1. Radon Exposure System. The radon exposure system is shown in Figure 1(a). Approximately $8000 \mathrm{~g}$ of the "Doll Stone" radon source (Ningyotoge Gensiryoku Sangyo, Co., Ltd., Okayama, Japan) was placed under a mouse cage in a radon exposure box $(370 \mathrm{~mm} \times 260 \mathrm{~mm} \times 272 \mathrm{~mm})$ to generate the conditions for radon inhalation. Air was blown into the box at a rate of $0.5 \mathrm{~L} / \mathrm{min}$ using an air pump, and an exhaust vent was opened. Mice had free access to food and water during radon inhalation. The radon concentration in the mouse cage was measured using a radon monitor (CRM-510, Measure Work, Chiba, Japan). The mean radon concentrations were approximately 20 (background) and $4000 \mathrm{~Bq} / \mathrm{m}^{3}$, respectively.

2.2. Experimental Protocol. Male C57BL/6J mice (age: eight weeks; weight: approximately $20 \mathrm{~g}$ ) were obtained from the Department of Animal Resources Advanced Science Research Center, Okayama University, Okayama, Japan. Ethics approval was obtained from the animal experimental committee of Okayama University. The study protocol was in accordance with the animal experimental guidelines of Okayama University. Each experimental group consisted of 4-6 mice.

Mice inhaled radon at a concentration of $4000 \mathrm{~Bq} / \mathrm{m}^{3}$ for 24 hours. Then, $5 \mathrm{~g} / \mathrm{kg}$ bodyweight of alcohol or saline solution (control) was injected into the peritoneum of the mice. Six or twenty-four hours after alcohol administration, blood was drawn from the heart for serum analysis, and livers were quickly excised to analyze the levels of SOD, catalase, tGSH, GPx, GR, TG, and lipid peroxide. Serum was separated by centrifugation at $3000 \times \mathrm{g}$ for $5 \mathrm{~min}$ for assays of GOT and GPT, activity and the TG, T-CHO, and protein levels. These samples were preserved at $-80^{\circ} \mathrm{C}$ until biochemical assay. Liver tissue samples were fixed in 10\% neutral-buffered formalin for histological examinations.

2.3. Biochemical Assays. The serum activity of GOT and GPT, serum levels of TG and T-CHO, and the levels of TG in the liver were measured using TA-LN kainosu, TG-EN kainosu, and T-CHO kainosu, respectively (Kainosu Co., Ltd., Tokyo, Japan), according to the manufacturer's recommendations.

The protein content was measured by the Bradford method, using the Protein Quantification Kit-Rapid (Dojindo Molecular Technologies, Inc., Kumamoto, Japan) [20].

Lipid peroxide (malondialdehyde (MDA)) levels were assayed using the Bioxytech LPO-586 assay kit (OXIS Health Products, Inc., Portland, OR, USA). Briefly, livers were homogenized in $20 \mathrm{mM}$ phosphate buffer (PBS; pH 7.4) on ice. Prior to homogenization, $10 \mu \mathrm{L}$ of $0.5 \mathrm{M}$ butylated hydroxytoluene in acetonitrile were added per $1 \mathrm{~mL}$ of tissue homogenate. After homogenization, the homogenate was centrifuged at $15000 \times \mathrm{g}$ for $10 \mathrm{~min}$ at $4^{\circ} \mathrm{C}$ and the supernatant was used for the assay. The MDA assay is based on the reaction of a chromogenic reagent, $\mathrm{N}$-methyl-2-phenylidole, with $\mathrm{MDA}$ at $45^{\circ} \mathrm{C}$. The optical density of the colored products was read at $586 \mathrm{~nm}$ on a spectrophotometer.

Mouse liver was homogenized in a $1 \mathrm{M}$ Tris- $\mathrm{HCl}$ buffer containing $5 \mathrm{mM}$ ethylenediaminetetraacetic acid (EDTA) ( $\mathrm{pH}$ 7.4) on ice. The homogenate was centrifuged at $12000 \times \mathrm{g}$ for $45 \mathrm{~min}$ at $4^{\circ} \mathrm{C}$, and the supernatant was used to assay the activity of SOD and catalase.

SOD activity was measured by the nitroblue tetrazolium (NBT) reduction method [21] using the Wako-SOD test (Wako Pure Chemical Industries, Co., Ltd., Osaka, Japan). Briefly, the extent of inhibition of NBT reduction was measured at $560 \mathrm{~nm}$ using a spectrophotometer. One unit of enzyme activity was defined as 50\% inhibition of NBT reduction.

Catalase activity was measured as the $\mathrm{H}_{2} \mathrm{O}_{2}$ reduction rate at $37^{\circ} \mathrm{C}$ and was assayed at $240 \mathrm{~nm}$ using a spectrophotometer [22]. The assay mixture consisted of $50 \mu \mathrm{L}$ of $1 \mathrm{M}$ Tris- $\mathrm{HCl}$ buffer containing $5 \mathrm{mM}$ EDTA (pH 7.4), $900 \mu \mathrm{L}$ of $10 \mathrm{mM} \mathrm{H}_{2} \mathrm{O}_{2}, 30 \mu \mathrm{L}$ deionized water, and $20 \mu \mathrm{L}$ liver supernatant. Activity was calculated using a molar extinction coefficient of $7.1 \times 10^{-3} \mathrm{M}^{-1} \mathrm{~cm}^{-1}$. Catalase activity was measured by the amount of hydrogen peroxide split by 
catalase in 20,40 , or $60 \mathrm{sec}$ at $37^{\circ} \mathrm{C}$. The reactions were started by addition of the liver supernatant.

Total glutathione content was measured using the Bioxytech GSH-420 assay kit (OXIS Health Products). Briefly, livers were homogenized in $10 \mathrm{mM}$ phosphate buffer ( $\mathrm{pH} 7.4$ ) on ice and then mixed with ice-cold $7.5 \%$ trichloroacetic acid solution. The homogenates were centrifuged at $3000 \times \mathrm{g}$ for $10 \mathrm{~min}$. The supernatant was used for the assay. Total glutathione content was measured at $420 \mathrm{~nm}$ using a spectrophotometer. This assay is based on the formation of a chromophoric thione, the absorbance of which, measured at $420 \mathrm{~nm}$, is directly proportional to the total glutathione concentration.

GPx activity was measured using the Bioxytech GPx340 assay kit (OXIS Health Products, Inc.). Briefly, liver samples were homogenized in $1 \mathrm{M}$ Tris- $\mathrm{HCl}$ buffer $(\mathrm{pH}$ 7.4) containing $5 \mathrm{mM}$ EDTA and $1 \mathrm{mM}$ dithiothreitol. The homogenates were centrifuged at $10000 \times \mathrm{g}$ for $20 \mathrm{~min}$ at $4^{\circ} \mathrm{C}$. The supernatants were used for the assay. The reduction of nicotinamide adenine dinucleotide phosphate (NADPH) to nicotinamide adenine dinucleotide phosphate $\left(\mathrm{NADP}^{+}\right)$ is accompanied by a decrease in absorbance, measured at $340 \mathrm{~nm}$, providing a spectrophotometric means for monitoring GPx enzyme activity. The molar extinction coefficient for NADPH is $6220 \mathrm{M}^{-1} \mathrm{~cm}^{-1}$ at $340 \mathrm{~nm}$. To assay GPx, the supernatant is added to a solution containing glutathione, GR, and NADPH. The enzyme reaction is initiated by adding a substrate, tert-butyl hydroperoxide, and absorbance at $340 \mathrm{~nm}$ is recorded for $3 \mathrm{~min}$.

GR activity was assayed using the Bioxytech GR-340 assay kit (OXIS Health Products, Inc.). Briefly, liver samples were homogenized in $1 \mathrm{M}$ Tris-HCl buffer with $5 \mathrm{mM}$ EDTA acid ( $\mathrm{pH} 7.4$ ) on ice. The homogenates were centrifuged at $8500 \times \mathrm{g}$ for $10 \mathrm{~min}$, and the supernatants were used for the assay. The assay is based on the oxidation of NADPH to $\mathrm{NADP}^{+}$, catalyzed by a limiting concentration of GR. One GR activity unit is defined as the amount of enzyme that catalyzes the reduction of $1 \mu \mathrm{mol}$ of oxidized glutathione (GSSG) per minute at $\mathrm{pH} 7.4$ and $25^{\circ} \mathrm{C}$. The reduction of GSSG is determined indirectly by measuring the consumption of NADPH, as demonstrated by a decrease in absorbance at $340 \mathrm{~nm}$ as a function of time.

2.4. Histological Examination. Liver samples were fixed in $10 \%$ formalin, processed through a graded ethanol series and finally xylene, and embedded in paraffin. Sixmicrometer-thick tissue sections were prepared and stained with hematoxylin-eosin (HE).

2.5. Statistical Analyses. Data are presented as the mean \pm standard error of the mean (SEM). Statistically significant differences between two groups were determined using Student's $t$-test.

\section{Results}

3.1. Changes in the Radon Concentration. Radon concentrations in the mouse cages are shown in Figures 1(b) and

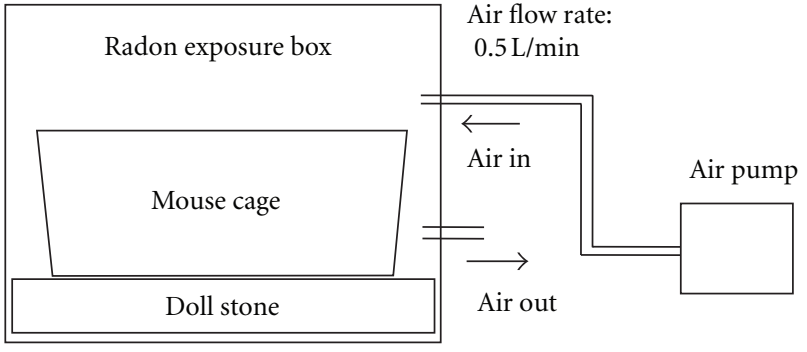

(a)

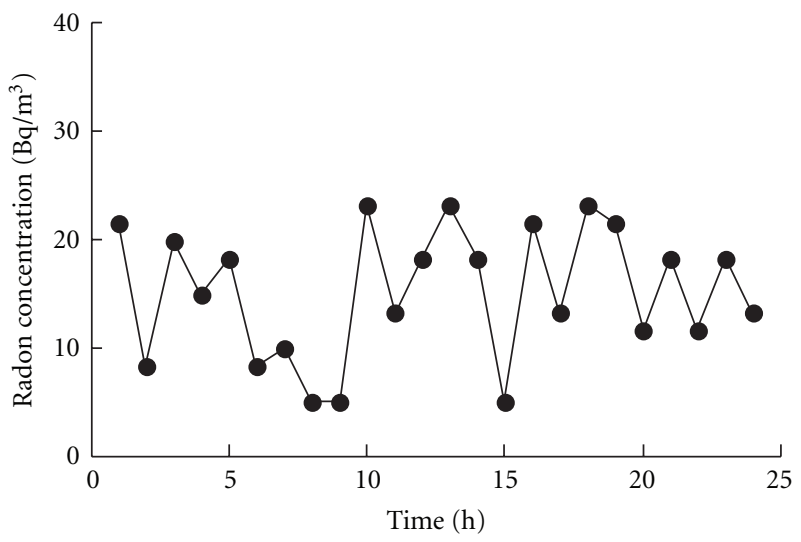

(b)

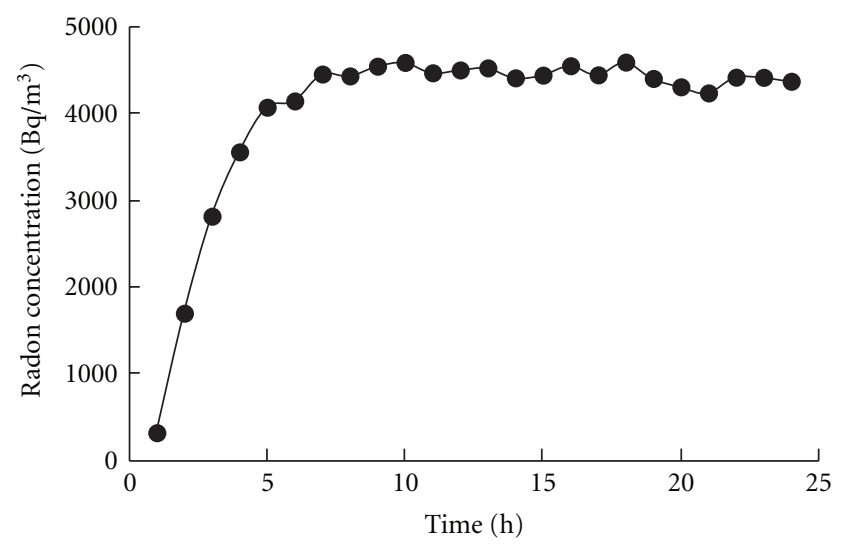

(c)

Figure 1: Schematic diagram of the radon exposure system (a). Changes in the radon concentration in the mouse cage over the period of sham (b) or radon inhalation (c).

1(c). The mean concentrations of background and treatment radon were approximately $20 \mathrm{~Bq} / \mathrm{m}^{3}$ and $4000 \mathrm{~Bq} / \mathrm{m}^{3}$, respectively.

3.2. Effects of Radon Inhalation on Hepatic Functions following Alcohol Administration. To assess the effects of radon inhalation on alcohol-induced hepatopathy, various parameters of hepatic functions were assayed in serum following radon inhalation. First, it was assessed whether alcohol administration induces acute alcohol-induced hepatopathy. Six hours after alcohol administration in the absence of radon (sham), the activities of GOT and GPT in serum were significantly higher $(P<0.001)$, and the TG $(P<0.01)$ and protein 


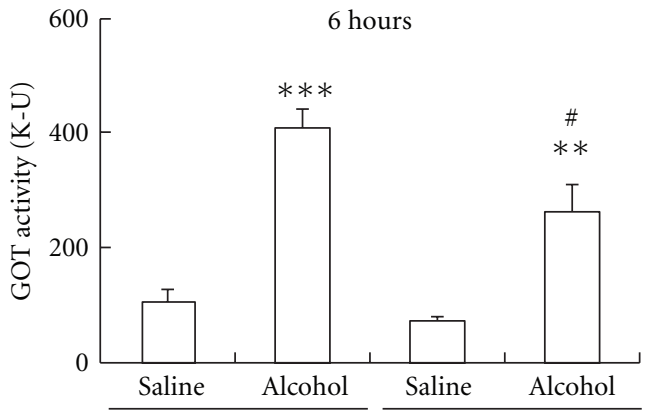

(a)

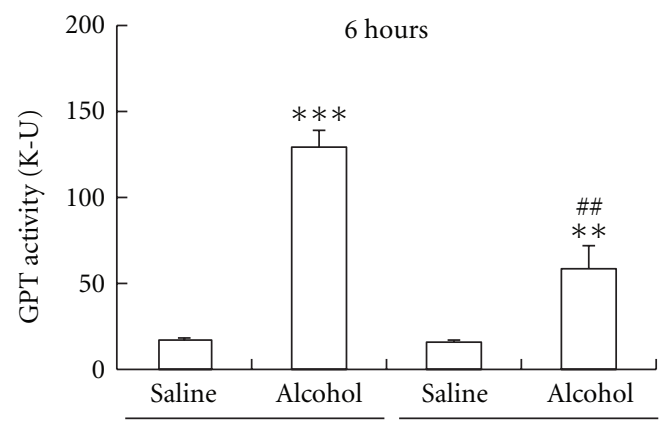

(c)

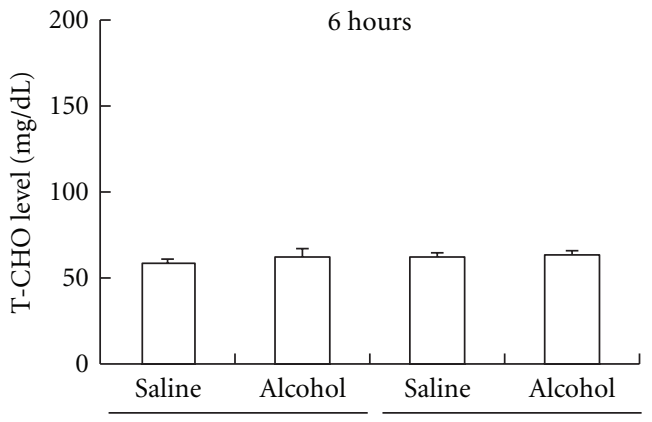

(e)

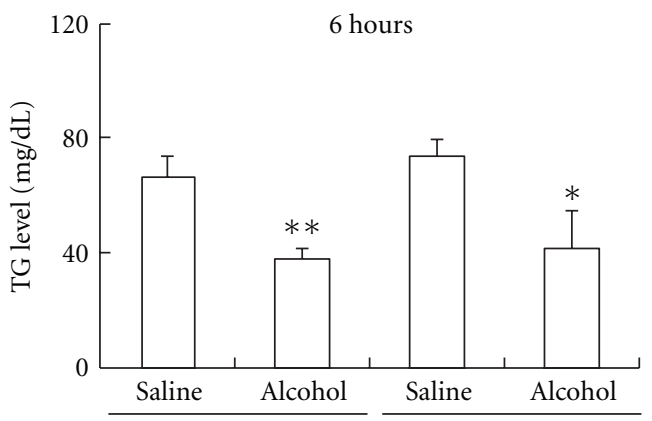

(g)

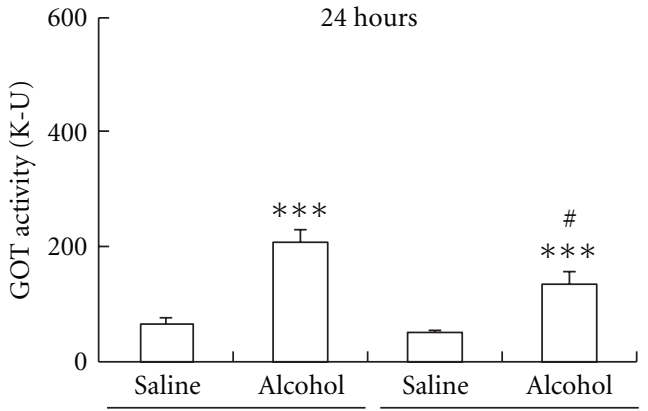

(b)

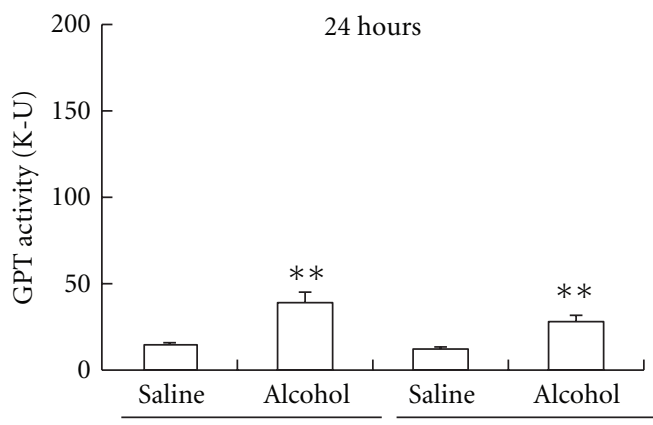

(d)

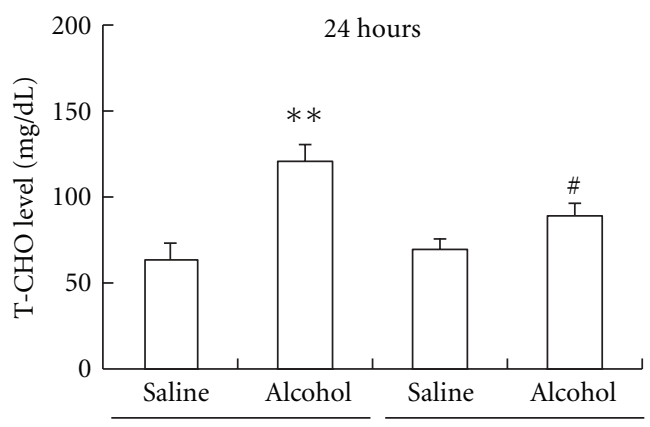

(f)

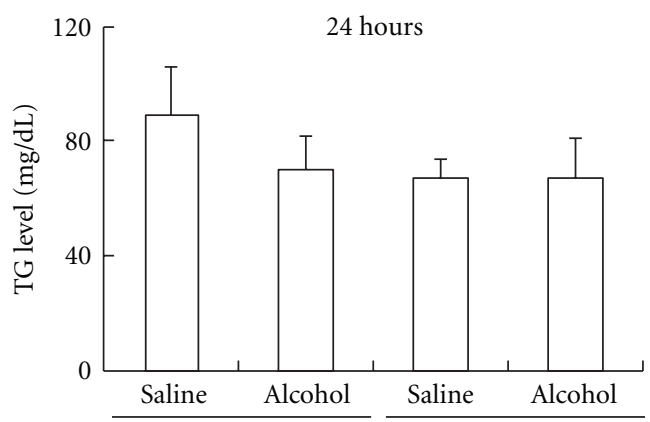

(h)

Figure 2: Continued. 


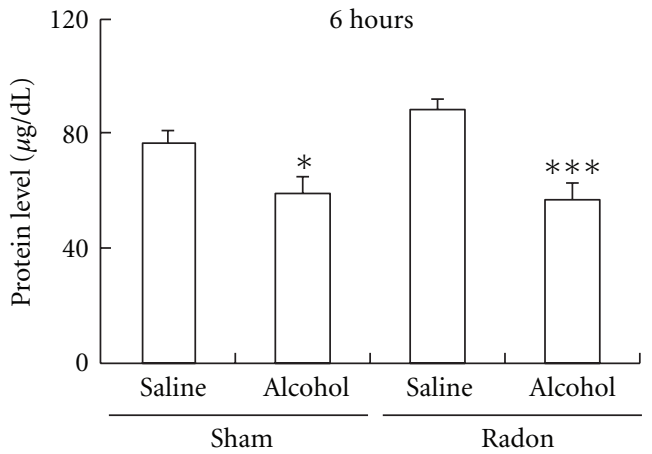

(i)

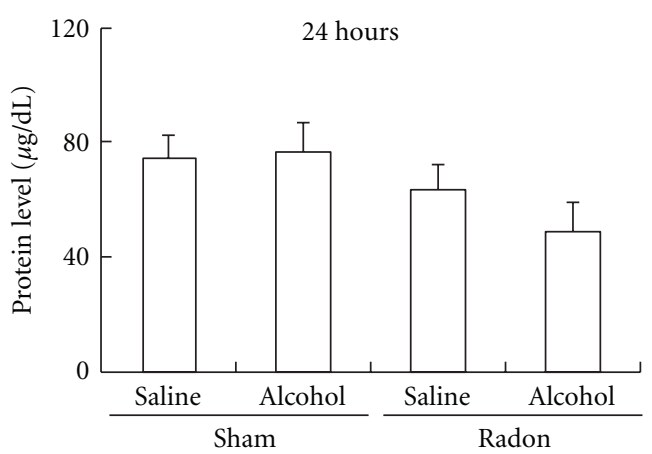

(j)

FIGURE 2: Effects of radon inhalation on hepatic function-associated parameters in the serum of alcohol-administrated mice. Each value indicates the mean \pm SEM. The number of mice per experimental point is $4-6$. ${ }^{*} P<0.05,{ }^{* *} P<0.01,{ }^{* * *} P<0.001$ versus each saline administrated mice. ${ }^{\#} P<0.05,{ }^{\#} P<0.01$ versus sham-inhaled and alcohol-administrated mice.

level $(P<0.05)$ in serum were significantly lower than in saline-administrated mice. Twenty-four hours after alcohol administration in the absence of radon, the activities of GOT $(P<0.001)$, GPT $(P<0.01)$, and T-CHO $(P<0.01)$ in serum were significantly higher than in saline-administrated animals (Figure 2). Six hours after alcohol administration following radon inhalation, the activities of GOT and GPT in serum were significantly higher $(P<0.01)$ and the TG $(P<$ $0.05)$ and protein $(P<0.001)$ in serum were significantly lower than in radon-inhaled and saline-administrated mice. Twenty-four hours after alcohol administration following radon inhalation, the activities of GOT $(P<0.001)$ and GPT $(P<0.01)$ in serum were significantly higher than in radoninhaled and saline-administrated mice (Figure 2).

Next, we assessed whether radon inhalation inhibits acute alcohol-induced hepatopathy. In mice injected with alcohol following radon inhalation, GOT activities in serum were significantly lower $(6 \mathrm{~h}$ or $24 \mathrm{~h}, P<0.05)$ than in shaminhaled and alcohol-administrated mice. Similarly, GPT activity $(6 \mathrm{~h}, P<0.01)$ and T-CHO $(24 \mathrm{~h}, P<0.05)$ in the serum of radon-inhaled mice were significantly lower than in sham-inhaled and alcohol-administrated mice (Figure 2).

3.3. Effects of Radon Inhalation on TG Level in Liver following Alcohol Administration. To assess the effects of radon inhalation on alcohol-induced fatty liver, TG level in the liver was assayed following radon inhalation. First, we assessed whether alcohol administration induces fatty liver. Twentyfour hours after alcohol administration in the absence of radon, the TG level in the liver was significantly higher $(P<$ 0.001 ) than in saline-administrated animals (Figure $3(\mathrm{a})$ ). Twenty-four hours after alcohol administration following radon inhalation, the TG level in the liver was significantly higher $(P<0.05)$ than in radon-inhaled and saline-administrated mice (Figure 3(a)).

Next, we assessed whether radon inhalation inhibits fatty liver. Twenty-four hours after alcohol administration, the TG level in the liver was $25 \%$ lower in radon-pretreated and alcohol-administrated animals than in sham-inhaled and alcohol-administrated animals, but this difference was not significant (Figure 3(a)).

3.4. Histological Observation in Livers following Alcohol Administration. To reveal which part of the liver has the most fatty degeneration, hepatocytes were examined following alcohol administration. Centrilobular hepatocytes were vacuolated following alcohol administration (Figures 3(d) and 3(f)). Periportal hepatocytes were also vacuolated following alcohol administration, but the vacuole formation of centrilobular hepatocytes was greater than in periportal hepatocytes (Figures 3(e) and 3(g)). No vacuole formation was observed in hepatocytes in saline-administrated mice (Figures 3(b) and 3(c)).

\subsection{Effects of Radon Inhalation on Oxidative Damage in} Liver following Alcohol Administration. To assess the effects of radon inhalation on alcohol-induced oxidative damage, lipid peroxide level in the liver was assayed following radon inhalation. First, we assessed whether alcohol administration induces oxidative damage. Six or twenty-four hours after alcohol administration in the absence of radon, lipid peroxide in the liver was significantly higher $(6 \mathrm{~h}$ or $24 \mathrm{~h}$, $P<0.01$ and $P<0.05$, resp.) than in sham-inhaled and saline-administrated mice (Figure 4).

Next, we assessed whether radon inhalation inhibits oxidative damage induced by alcohol administration. Six or twenty-four hours after alcohol administration following radon inhalation, lipid peroxide in the liver was significantly lower $(P<0.05)$ than in sham-inhaled and alcoholadministrated mice (Figure 4 ).

3.6. Effects of Radon Inhalation on Antioxidative Functions in Liver following Alcohol Administration. To clarify the mechanisms underlying the inhibitory effect of radon inhalation on acute alcohol-induced hepatopathy, antioxidant-associated substances such as SOD, catalase, t-GSH, GPx, and GR were examined. First, we assessed whether radon inhalation activates antioxidative functions in the liver. In mice injected with saline following radon inhalation, catalase activity and 

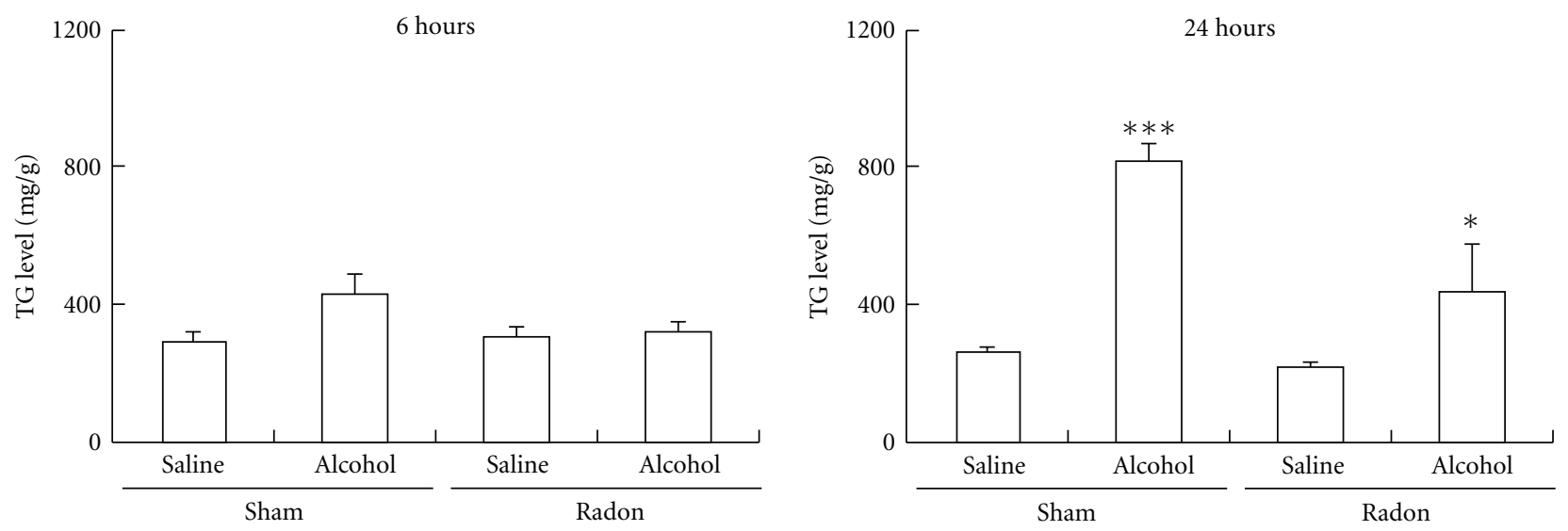

(a)

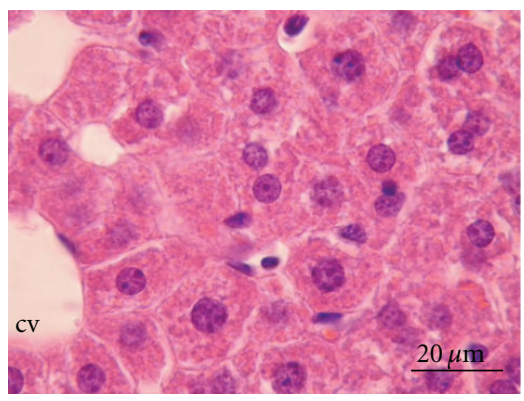

(b)

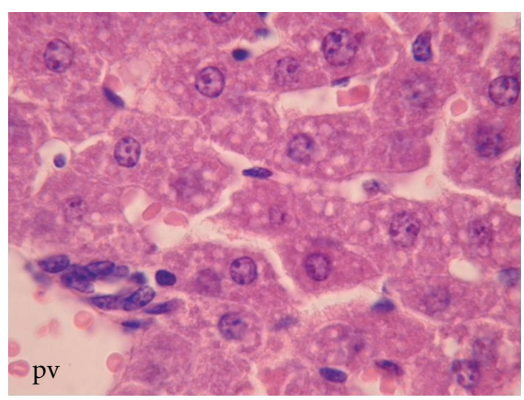

(e)

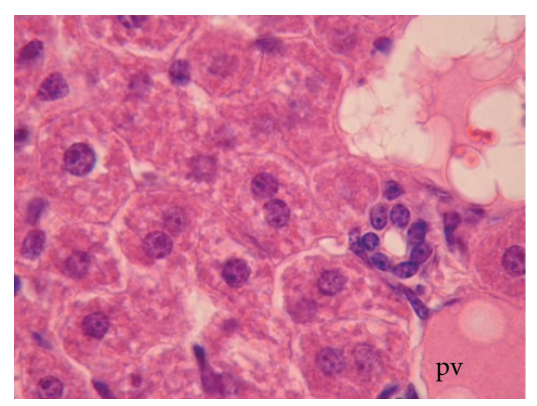

(c)

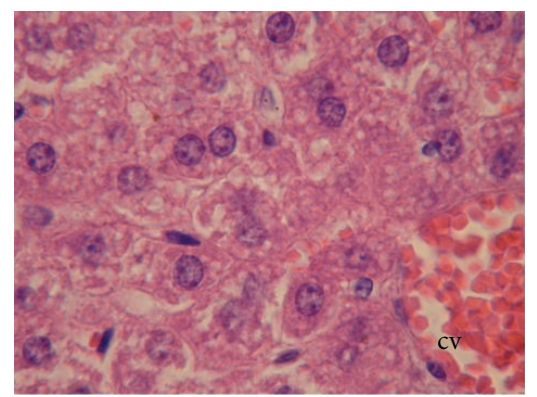

(f)

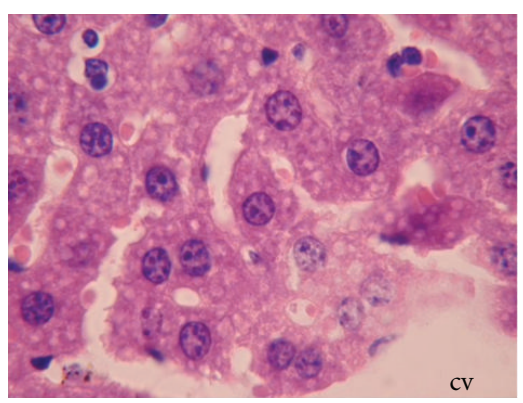

(d)

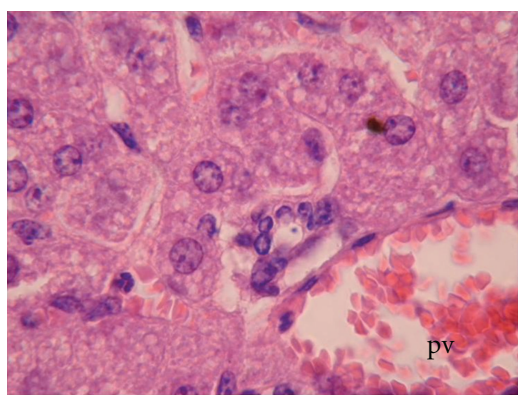

(g)

FIgURE 3: Effects of radon inhalation on TG level in liver (a) and histological changes in mouse liver after 24 hours following alcohol administration. (b), (c) sham inhalation before saline administration; (d), (e) sham inhalation before alcohol administration; (f), (g) radon inhalation before alcohol administration. The length of the scale bar is $20 \mu \mathrm{m}$. All samples were stained with HE. The area of the vacuole formations surrounding the central vein $(\mathrm{cv})$ and portal vein $(\mathrm{pv})$. Each value indicates the mean \pm SEM. The number of mice per experimental point is $4-6 .{ }^{*} P<0.05,{ }^{* * *} P<0.001$ versus each saline-administrated mice.

$\mathrm{t}$-GSH content in the liver $(6 \mathrm{~h}, P<0.05)$ and the activities of SOD $(24 \mathrm{~h}, P<0.01)$ and GPx $(24 \mathrm{~h}, P<0.05)$ in the liver were significantly higher than in sham-inhaled and salineadministrated mice (Figure 5).

Next, we assessed whether alcohol administration depresses antioxidative functions in the liver. Six hours after alcohol administration in the absence of radon, the activities of SOD $(P<0.05)$, catalase $(P<0.05)$, and GR $(P<0.01)$ and t-GSH content $(P<0.001)$ in the liver were significantly lower than in sham-inhaled and saline-administrated mice. Similarly, 24 hours after alcohol administration in the absence of radon, the activities of catalase $(P<0.05)$ and GR $(P<0.001)$ and $\mathrm{t}-\mathrm{GSH}$ content $(P<0.01)$ in the liver were significantly lower than in saline-administrated and sham-inhaled mice. Six hours after alcohol administration following radon inhalation, the activities of GPx and GR and t-GSH content in the liver were significantly lower $(P<0.05)$ than in radon-inhaled and saline-administrated mice. Similarly, 24 hours after alcohol administration following radon inhalation, the activities of GPx $(P<0.05)$ and GR $(P<0.01)$ and $\mathrm{t}-\mathrm{GSH}$ content $(P<0.05)$ in the liver were significantly lower than in radoninhaled and saline-administrated mice (Figure 5).

Furthermore, we assessed whether radon inhalation activates antioxidative functions following alcohol administration. Six hours after alcohol administration following 

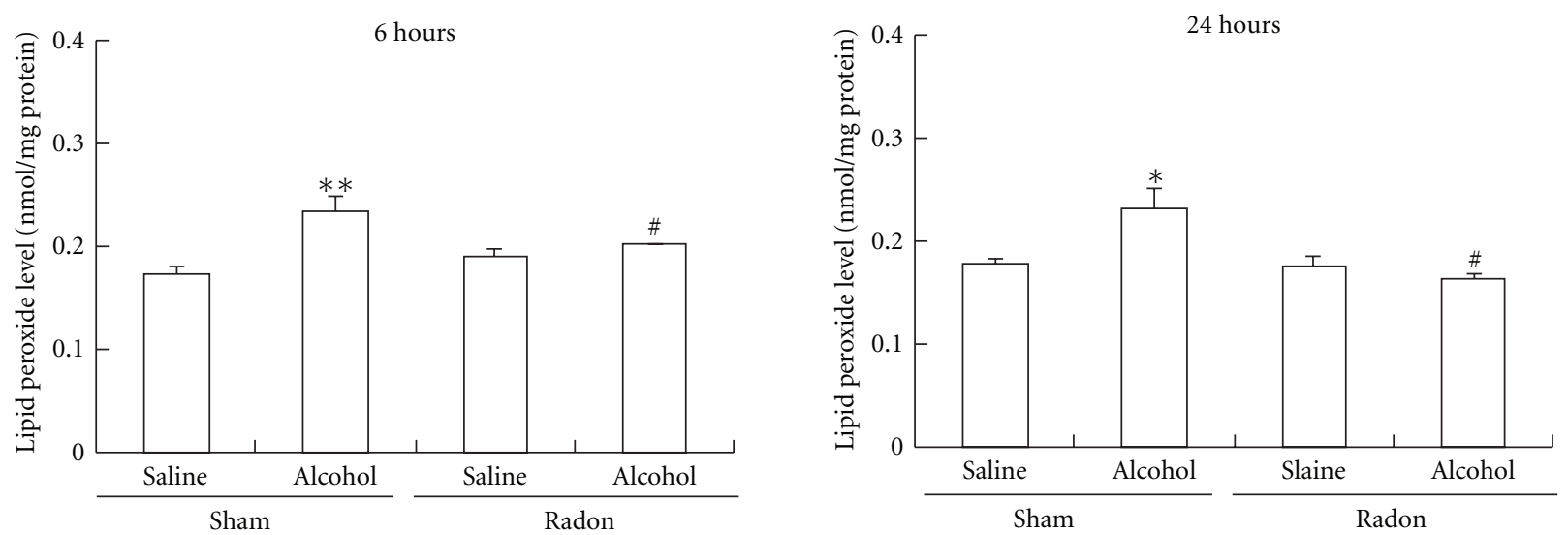

FIGURE 4: Effects of radon inhalation on lipid peroxide level in liver after alcohol administration. Each value indicates the mean \pm SEM. The number of mice per experimental point is 5-6. ${ }^{*} P<0.05,{ }^{* *} P<0.01$ versus each saline-administrated mice, ${ }^{*} P<0.05$ versus sham inhaled and alcohol-administrated mice.

radon inhalation, the activities of SOD, catalase, and GR and t-GSH content in the liver were significantly higher $(P<$ $0.05)$ than in sham-inhaled and alcohol-administrated mice. Similarly, 24 hours after alcohol administration following radon inhalation, catalase activity $(P<0.05)$ and t-GSH content $(P<0.05)$ in the liver were significantly higher than in sham-inhaled and alcohol-administrated mice (Figure 5).

\section{Discussion}

Low-dose irradiation promotes a small induction of ROS in vivo and induces the production of antioxidant substances, including SOD, catalase and glutathione, in various organs [23-25]. Previous studies have shown that low-dose Xirradiation enhances antioxidative functions in the liver of mice [26] and reduces oxidative damage such as ischemiareperfusion injury [27], cold injury [28], and liver damage [29-31]. It appears to be highly possible that low-dose Xirradiation helps to prevent or reduce ROS-related damage.

Recently, we have reported that radon inhalation has an effect similar to X-irradiation. For example, radon inhalation activates antioxidative functions in many organs of mice and inhibits $\mathrm{CCl}_{4}$-induced liver and renal damage $[18,32$, $33]$, type- 1 diabetes $[8]$, and pain $[8,34]$. Interestingly, the absorbed dose of radon is much lower than $\mathrm{X}$-irradiation. Our previous study suggested that radon inhalation at a concentration of $4000 \mathrm{~Bq} / \mathrm{m}^{3}$ for 12 hours activated increased SOD activity in mouse liver [7]. According to Sakoda's report [12], the absorbed dose by the liver was approximately $300 \mathrm{nGy}$ under experimental conditions; however, the absorbed dose does not include exposure to radiation from the radon progeny concentration. Therefore, our radon exposure system in the present study probably has a slightly higher absorbed dose by the lungs because the radon progeny concentration is uncontrolled.

Production of free radicals contributes to the development of alcohol-induced liver damage [14-17]. Alcohol administration has been found to cause the accumulation of ROS, including $\mathrm{O}_{2}{ }^{-}$, ${ }^{-} \mathrm{OH}$, and $\mathrm{H}_{2} \mathrm{O}_{2}$, and to increase lipid peroxide in the liver [16]. Alcohol administration leads to GSH depletion in the liver $[35,36]$, suggesting direct conjugation of GSH with acetaldehyde and reactive intermediates of alcohol oxidation. The results of this study show that not only t-GSH but also other antioxidant enzymes, such as SOD, catalase, and GR, decreased following alcohol administration. In addition, alcohol administration significantly increased lipid peroxide in the liver. These findings indicate that alcohol administration induced oxidative damage. Moreover, alcohol administration significantly increased GOT and GPT activities and T-CHO in serum and significantly decreased TG in serum. These findings suggest that alcohol administration induced hepatopathy. Furthermore, alcohol administration significantly increased TG in the liver, suggesting that alcohol administration induced fatty liver.

Our previous study suggested that radon inhalation at a concentration of $2000 \mathrm{~Bq} / \mathrm{m}^{3}$ for 24 hours significantly increased GPx activity and t-GSH content in mouse liver [18]. Another report suggested that activation of SOD activities induced by radon inhalation showed a dose-rate effect [7]. In fact, radon inhalation significantly increased catalase activity, t-GSH content, SOD activity, and GPx activity in the liver. These findings suggest that radon inhalation activated antioxidative functions in the liver.

The results of this study show that the activities of GOT and GPT in serum and the levels of TG and lipid peroxide in the liver of radon-inhaled and alcohol-administrated mice were significantly lower than those of sham-inhaled and alcohol-administrated mice. These findings suggest that radon inhalation inhibited acute alcohol-induced hepatopathy, fatty liver, and oxidative damage.

To clarify the mechanisms underlying the inhibitory effect of radon inhalation, we examined antioxidantassociated substances such as SOD, catalase, t-GSH, GPx and GR. Many studies have shown that administration of antioxidants agents can prevent alcohol-induced liver injury. For example, quercetin prevents ethanol-induced dyslipidemia 


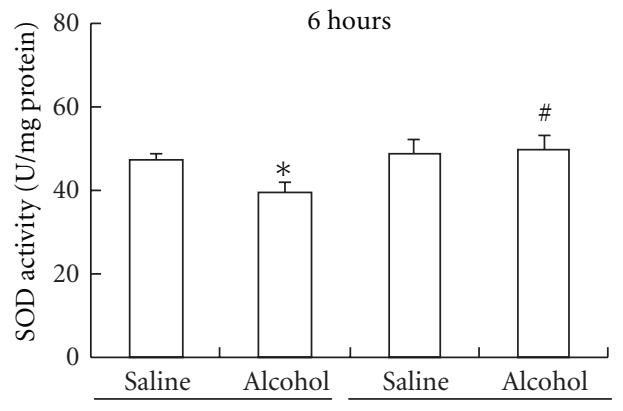

(a)

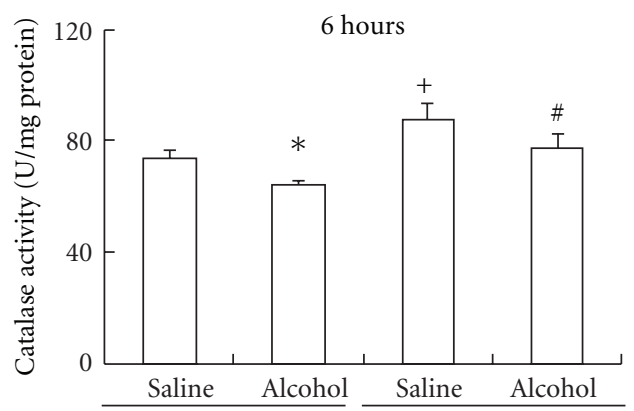

(c)

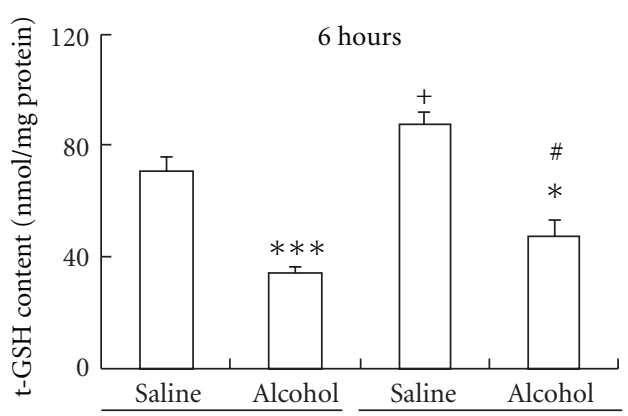

(e)

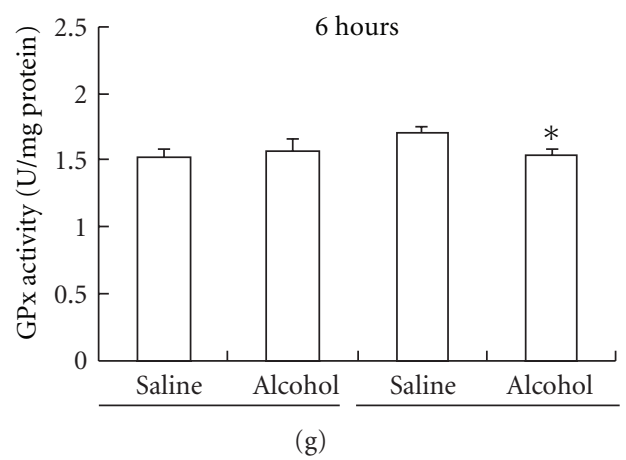

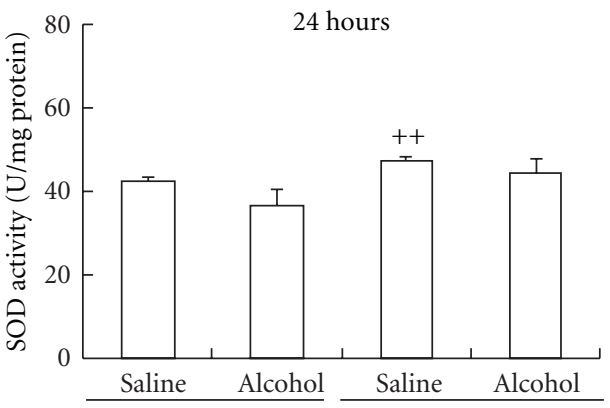

(b)

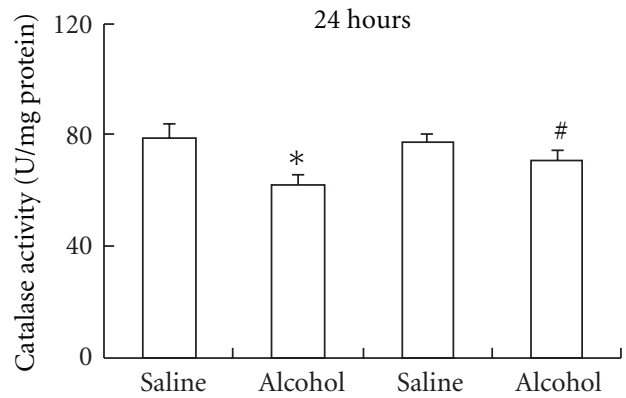

(d)

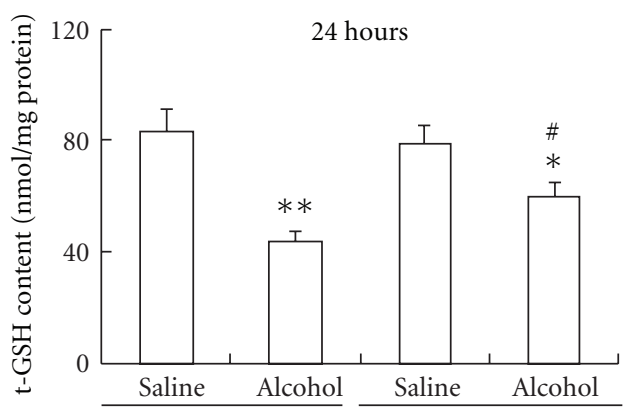

(f)

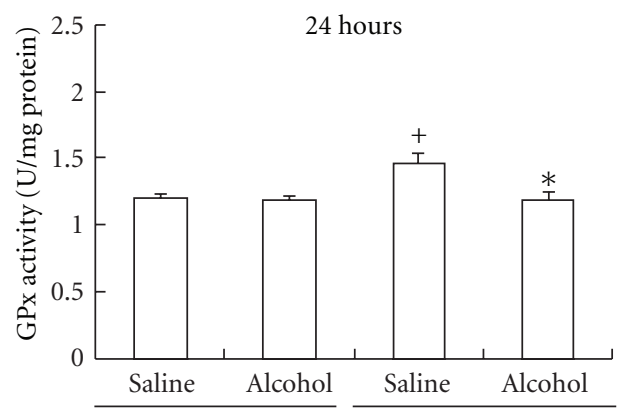

(h)

Figure 5: Continued. 


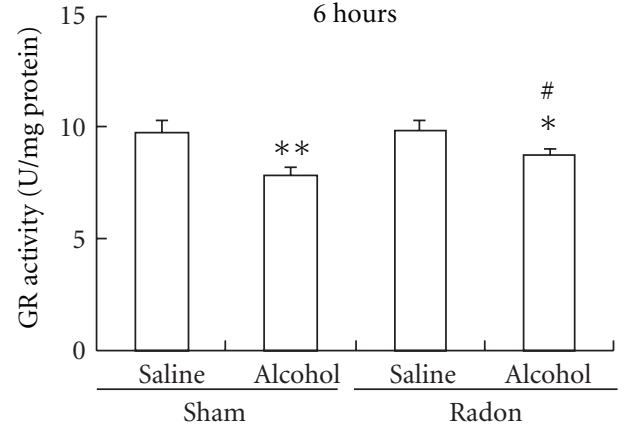

(i)

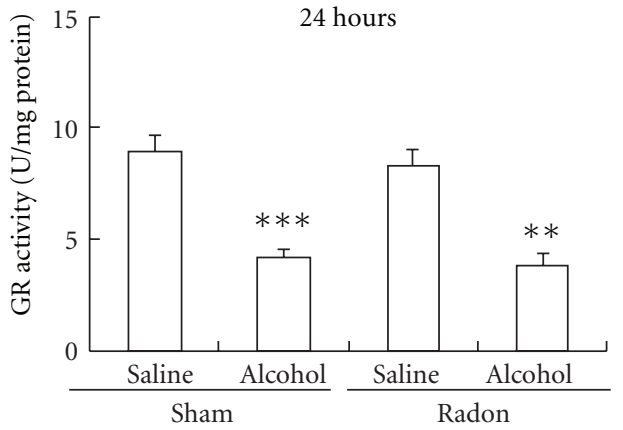

(j)

FIGURE 5: Effects of radon inhalation on antioxidative-associated parameters in mouse liver after alcohol administration. Each value indicates the mean \pm SEM. The number of mice per experimental point was $5-6 .{ }^{*} P<0.05,{ }^{* *} P<0.01$, and ${ }^{* * *} P<0.001$ versus each salineadministrated mice, ${ }^{\#} P<0.05$, versus sham inhaled and alcohol-administrated mice, and ${ }^{+} P<0.05,{ }^{++} P<0.01$ versus sham-inhaled and saline-administrated mice.

and mitochondrial oxidative damage [37]. Another report suggested that Emblica officinalis prevents ethanol-induced hepatic injury by ameliorating oxidative stress [38]. In this study, antioxidative functions in the liver of radon-inhaled and alcohol-administrated mice were significantly higher than in sham-inhaled and alcohol-administrated mice. These findings suggest that radon inhalation inhibits acute alcoholinduced hepatopathy in mice due to the activation of antioxidative functions induced by radon inhalation.

\section{Conclusion}

Radon inhalation activates antioxidative functions and inhibits not only acute alcohol-induced oxidative damage but also hepatopathy and fatty liver in mice. The activation of antioxidative functions induced by radon inhalation may detoxify ROS induced by alcohol metabolism. Radon therapy is performed for various diseases at Misasa Medical Center, Okayama University Hospital, Okayama Japan. Hepatic damage is not the main indication for radon therapy; however, our study strongly suggests that radon therapy is useful in the prevention of alcohol-induced hepatopathy.

\section{Acknowledgment}

The authors thank Mr. Izumi Mifune (Ningyotoge Gensiryoku Sangyo, Co., Ltd., Okayama, Japan) for his kind gift of the Doll Stone.

\section{References}

[1] K. Yamaoka, F. Mitsunobu, K. Hanamoto, S. Mori, Y. Tanizaki, and K. Sugita, "Study on biologic effects of radon and thermal therapy on osteoarthritis," Journal of Pain, vol. 5, no. 1, pp. 20-25, 2004.

[2] K. Yamaoka, F. Mitsunobu, K. Hanamoto et al., "Biochemical comparison between radon effects and thermal effects on humans in radon hot spring therapy," Journal of Radiation Research, vol. 45, no. 1, pp. 83-88, 2004.
[3] Y. Aoyama, T. Kataoka, S. Nakagawa et al., "Study on effects of thoron and thermal treatment for aging-related diseases on humans," Iranian Journal of Radiation Research, vol. 9, no. 4, pp. 221-229, 2012.

[4] T. Kataoka, Y. Aoyama, A. Sakoda, S. Nakagawa, and K. Yamaoka, "Basic study on biochemical mechanism of thoron and thermal therapy," Physiological Chemistry and Physics and Medical NMR, vol. 38, no. 2, pp. 85-92, 2006.

[5] K. Becker, "One century of radon therapy," International Journal of Low Radiation, vol. 1, no. 3, pp. 334-357, 2004.

[6] F. Mitsunobu, K. Yamaoka, K. Hanamoto et al., "Elevation of antioxidant enzymes in the clinical effects of radon and thermal therapy for bronchial asthma," Journal of Radiation Research, vol. 44, no. 2, pp. 95-99, 2003.

[7] T. Kataoka, A. Sakoda, Y. Ishimori et al., "Study of the response of superoxide dismutase in mouse organs to radon using a new large-scale facility for exposing small animals to radon," Journal of Radiation Research, vol. 52, no. 6, pp. 775-781, 2011.

[8] T. Kataoka, J. Teraoka, A. Sakoda et al., "Protective effects of radon inhalation on carrageenan-induced inflammatory paw edema in mice," Inflammation, vol. 35, no. 2, pp. 713-722, 2012.

[9] B. W. Wheeler, J. Allen, M. H. Depledge, and A. Curnow, "Radon and skin cancer in southwest England: an ecologic study," Epidemiology, vol. 23, no. 1, pp. 44-52, 2012.

[10] A. R. Denman, J. P. Eatough, G. Gillmore, and P. S. Phillips, "Assessment of health risks to skin and lung of elevated radon levels in abandoned mines," Health Physics, vol. 85, no. 6, pp. 733-739, 2003.

[11] D. Krewski, J. H. Lubin, J. M. Zielinski et al., "Residential radon and risk of lung cancer: a combined analysis of 7 North American case-control studies," Epidemiology, vol. 16, no. 2, pp. 137-145, 2005.

[12] United Nations Scientific Committee on the Effects of Atomic Radiation (UNSCEAR), "Sources and effects of ionizing radiation,” Report, UNSCEAR, 1993.

[13] A. Sakoda, Y. Ishimori, A. Kawabe, T. Kataoka, K. Hanamoto, and K. Yamaoka, "Physiologically based pharmacokinetic modeling of inhaled radon to calculate absorbed doses in mice, rats, and humans," Journal of Nuclear Science and Technology, vol. 47, no. 8, pp. 731-738, 2010.

[14] A. Muller and H. Sies, "Role of alcohol dehydrogenase activity and of acetaldehyde in ethanol-induced ethane and pentane 
production by isolated perfused rat liver," Biochemical Journal, vol. 206, no. 1, pp. 153-156, 1982.

[15] O. R. Koch, T. Galeotti, G. M. Bartoli, and A. Boveris, "Alcohol-induced oxidative stress in rat liver," Xenobiotica, vol. 21, no. 8, pp. 1077-1084, 1991.

[16] A. Dey and A. I. Cederbaum, "Alcohol and oxidative liver injury," Hepatology, vol. 43, no. 2, supplement 1, pp. S63-S74, 2006.

[17] O. R. Koch, G. Pani, S. Borrello et al., "Oxidative stress and antioxidant defenses in ethanol-induced cell injury," Molecular Aspects of Medicine, vol. 25, no. 1-2, pp. 191-198, 2004.

[18] T. Kataoka, Y. Nishiyama, T. Toyota et al., "Radon inhalation protects mice from carbon-tetrachloride-induced hepatic and renal damage," Inflammation, vol. 34, no. 6, pp. 559-567, 2011.

[19] T. Kataoka, A. Sakoda, M. Yoshimoto et al., "A comparative study on effect of continuous radon inhalation on several-time acute alcohol-induced oxidative damages of liver and brain in mouse," Radiation Safety Management, vol. 10, no. 1, pp. 1-7, 2011.

[20] M. M. Bradford, "A rapid and sensitive method for the quantitation of microgram quantities of protein utilizing the principle of protein dye binding," Analytical Biochemistry, vol. 72, no. 1-2, pp. 248-254, 1976.

[21] R. L. Baehner, S. K. Murrmann, J. Davis, and R. B. Johnston, "The role of superoxide anion and hydrogen peroxide in phagocytosis associated oxidative metabolic reactions," Journal of Clinical Investigation, vol. 56, no. 3, pp. 571-576, 1975.

[22] H. Aebi, S. R. Wyss, B. Scherz, and J. Gross, "Properties of erythrocyte catalase from homozygotes and heterozygotes for Swiss type acatalasemia," Biochemical Genetics, vol. 14, no. 910, pp. 791-807, 1976.

[23] K. Yamaoka, R. Edamatsu, and A. Mori, "Increased SOD activities and decreased lipid peroxide levels induced by low dose X irradiation in rat organs," Free Radical Biology and Medicine, vol. 11, no. 3, pp. 299-306, 1991.

[24] K. Yamaoka, Y. Komoto, I. Suzuka, R. Edamatsu, and A. Mori, "Effects of radon inhalation on biological function-lipid peroxide level, superoxide dismutase activity, and membrane fluidity," Archives of Biochemistry and Biophysics, vol. 302, no. 1, pp. 37-41, 1993.

[25] S. Kojima, O. Matsuki, T. Nomura et al., "Induction of mRNAs for glutathione synthesis-related proteins in mouse liver by low doses of $\gamma$-rays," Biochimica et Biophysica Acta, vol. 1381, no. 3, pp. 312-318, 1998.

[26] T. Kataoka, M. Yoshimoto, S. Nakagawa, Y. Mizuguchi, T. Taguchi, and K. Yamaoka, "Basic study on active changes in biological function of mouse liver graft in cold storage after low-dose X-irradiation," Journal of Clinical Biochemistry and Nutrition, vol. 45, no. 2, pp. 219-226, 2009.

[27] T. Kataoka, Y. Mizuguchi, M. Yoshimoto, T. Taguchi, and K. Yamaoka, "Inhibitory effects of prior low-dose X-irradiation on ischemia-reperfusion injury in mouse paw," Journal of Radiation Research, vol. 48, no. 6, pp. 505-513, 2007.

[28] M. Yoshimoto, T. Kataoka, T. Toyota, T. Taguchi, and K. Yamaoka, "Inhibitory effects of prior low-dose X-irradiation on cold-induced brain injury in mouse," Inflammation, vol. 35, no. 1, pp. 89-97, 2012.

[29] T. Kataoka and K. Yamaoka, "Activation of biodefense system by low-dose irradiation or radon inhalation and its applicable possibility for treatment of diabetes and hepatopathy," ISRN Endocrinology, vol. 2012, Article ID 292041, 11 pages, 2012.

[30] T. Kataoka, T. Nomura, D. H. Wang, T. Taguchi, and K. Yamaoka, "Effects of post low-dose X-ray irradiation on carbon tetrachloride-induced acatalasemic mice liver damage,"
Physiological Chemistry and Physics and Medical NMR, vol. 37, no. 2, pp. 109-126, 2005.

[31] K. Yamaoka, T. Kataoka, T. Nomura et al., "Inhibitory effects of prior low-dose X-ray irradiation on carbon tetrachlorideinduced hepatopathy in acatalasemic mice," Journal of Radiation Research, vol. 45, no. 1, pp. 89-95, 2004.

[32] K. Kataoka, Y. Nishiyama, K. Yamato et al., "Comparative study on the inhibitory effects of antioxidant vitamins and on carbon tetrachloride-induced hepatopathy," Journal of Radiation Research, vol. 53, no. 6, pp. 830-839, 2012.

[33] K. Kataoka, K. Yamato, Y. Nishiyama et al., "Comparative study on the inhibitory effects of $\alpha$-tocopherol and radon on carbon tetrachloride-induced renal damage," Renal Failure, vol. 34, no. 9, pp. 1181-1187, 2012.

[34] K. Yamato, T. Kataoka, Y. Nishiyama, T. Taguchi, and K. Yamaoka, "Preventive and curative effects of radon inhalation on chronic constriction injury-induced neuropathic pain in mice," European Journal of Pain.

[35] B. L. Vogt and J. P. Richie, "Glutathione depletion and recovery after acute ethanol administration in the aging mouse," Biochemical Pharmacology, vol. 73, no. 10, pp. 1613-1621, 2007.

[36] O. Strubelt, M. Younes, and R. Pentz, "Enhancement by glutathione depletion of ethanol-induced acute hepatotoxicity in vitro and in vivo," Toxicology, vol. 45, no. 2, pp. 213-223, 1987.

[37] Y. Tang, C. Gao, M. Xing et al., "Quercetin prevents ethanolinduced dyslipidemia and mitochondrial oxidative damage," Food and Chemical Toxicology, vol. 50, no. 5, pp. 1194-1200, 2012.

[38] V. Damodara Reddy, P. Padmavathi, S. Gopi, M. Paramahamsa, and N. C. Varadacharyulu, "Protective effect of emblica officinalis against alcohol-induced hepatic injury by ameliorating oxidative stress in rats," Indian Journal of Clinical Biochemistry, vol. 25, no. 4, pp. 419-424, 2010. 


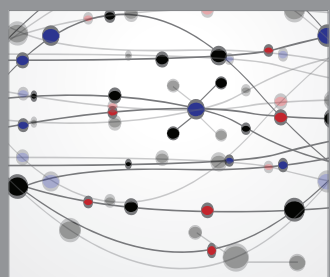

The Scientific World Journal
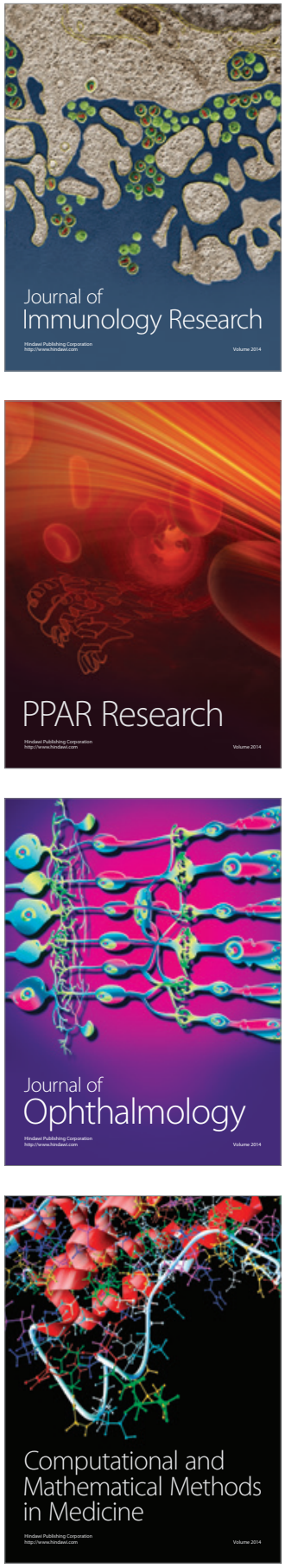

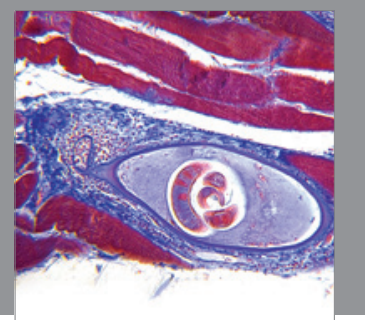

Gastroenterology

Research and Practice
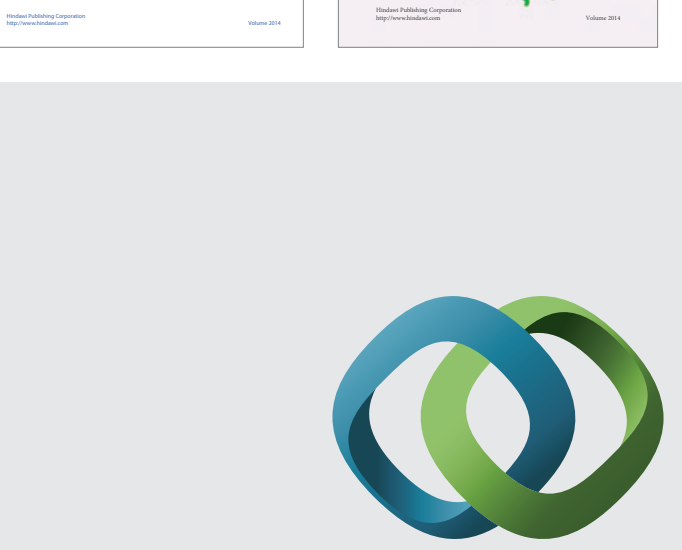

\section{Hindawi}

Submit your manuscripts at

http://www.hindawi.com
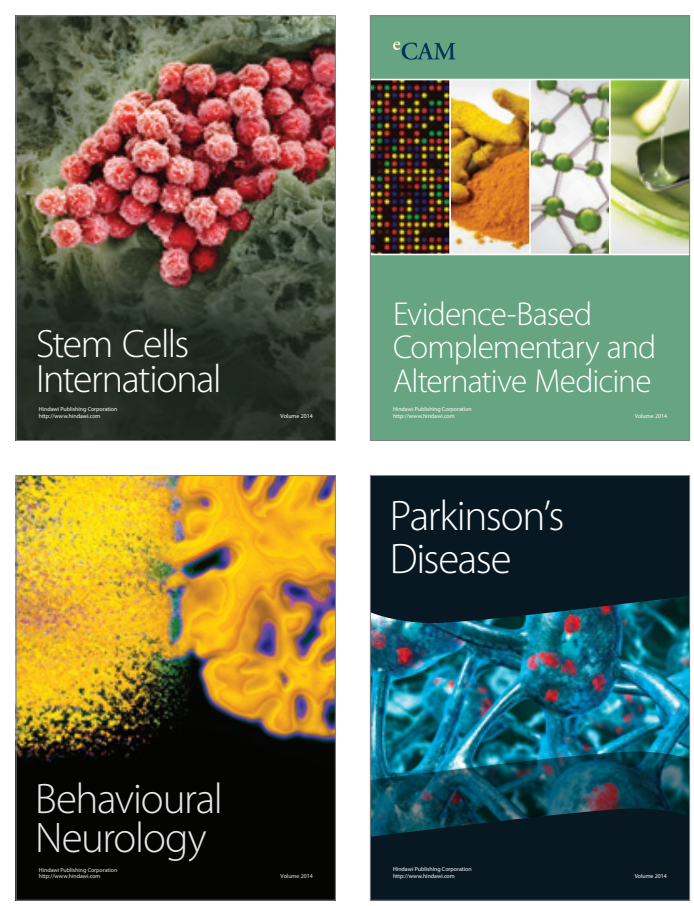

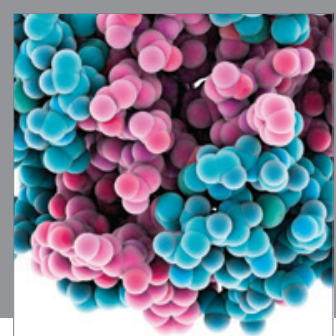

Journal of
Diabetes Research

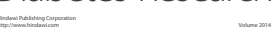

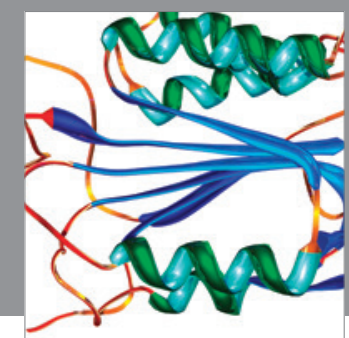

Disease Markers
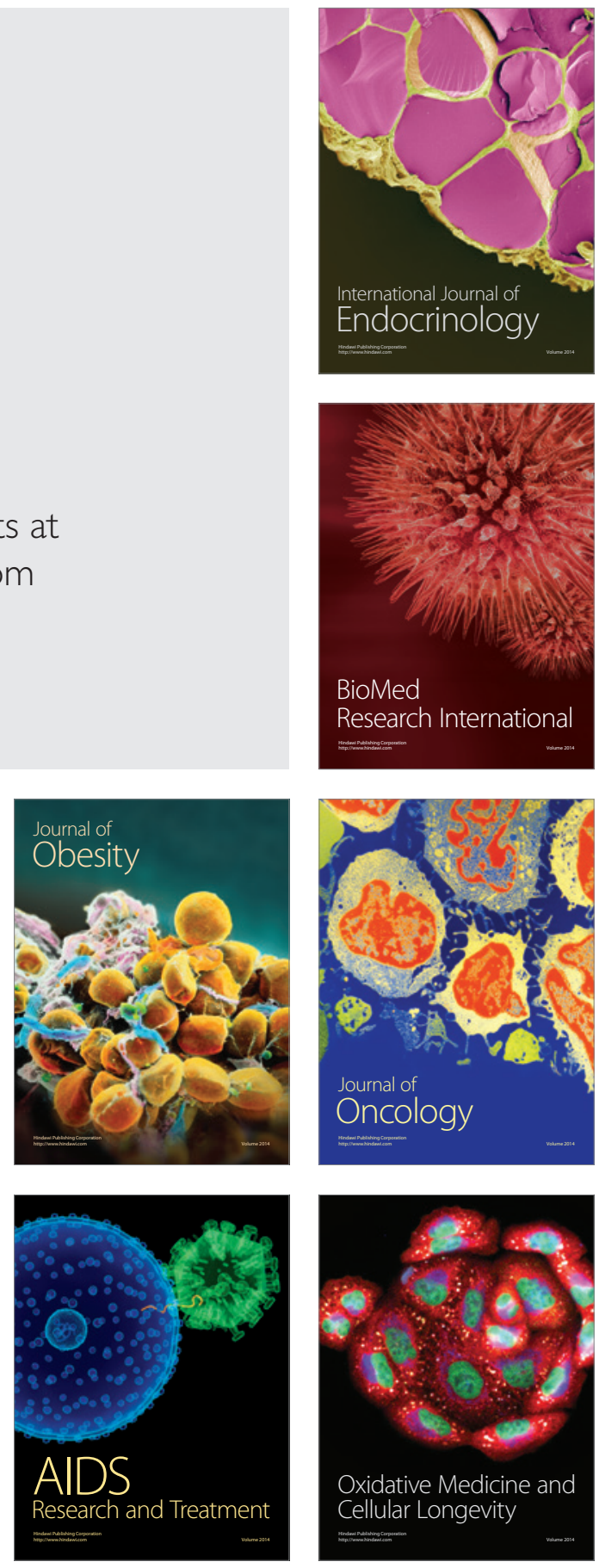